\title{
Determinants of poor adherence to secondary antibiotic prophylaxis for rheumatic fever recurrence on Lifou, New Caledonia: a retrospective cohort study
}

Brunelle Gasse ${ }^{1,2}$, Noémie Baroux², Bernard Rouchon ${ }^{3}$, Jean-Michel Meunier ${ }^{4}$, Isabelle De Frémicourt ${ }^{5}$ and Eric D'Ortenzio ${ }^{2 *}$

\begin{abstract}
Background: Incidence of acute rheumatic fever (ARF) and prevalence of rheumatic heart disease (RHD) in the Pacific region, including New Caledonia, are amongst the highest in the world. The main priority of long-term management of ARF or RHD is to ensure secondary prophylaxis is adhered to. The objectives of this study were to evaluate rates of adherence in people receiving antibiotic prophylaxis by intramuscular injections of penicillin in Lifou and to determine the factors associated with a poor adherence in this population.

Methods: We conducted a retrospective cohort study and we included 70 patients receiving injections of antibiotic prophylaxis to prevent ARF recurrence on the island of Lifou. Patients were classified as "good-adherent" when the rate of adherence was $\geq 80 \%$ of the expected injections and as "poor-adherent" when it was $<80 \%$. Statistical analysis to identify factors associated with adherence was performed using a multivariate logistic regression model.

Results: Our study showed that $46 \%$ of patients from Lifou receiving antibiotic prophylaxis for ARF or RHD had a rate of adherence $<80 \%$ and were therefore at high risk of recurrence of ARF. Three independent factors were protective against poor adherence: a household with more than five people (odds ratio, 0.25; 95\% confidence interval [Cl], 0.08 to 0.75 ), a previous medical history of symptomatic ARF (odds ratio, $0.20 ; 95 \% \mathrm{Cl}, 0.04$ to 0.98 ) and an adequate healthcare coverage (odds ratio, $0.21 ; 95 \% \mathrm{Cl} 0.06$ to 0.72 ).

Conclusions: To improve adherence to secondary prophylaxis in Lifou, we therefore propose the following recommendations arising from the results of this study: i) identifying patients receiving antibiotic prophylaxis without medical history of ARF to strengthen their therapeutic education and ii) improving the medical coverage in patients with ARF or RHD. We also recommend that the nurse designated for the ARF prevention program in Lifou coordinate an active recall system based on an updated local register. But the key point to improve adherence among Melanesian patients is probably to give appropriate information regarding the disease and the treatment, taking into account the Melanesian perceptions of the disease.
\end{abstract}

Keywords: Acute rheumatic fever, Rheumatic heart disease, Patient compliance, Antibiotic prophylaxis, Melanesia, New Caledonia

\footnotetext{
* Correspondence: ericdortenzio@gmail.com

${ }^{2}$ Institut Pasteur de Nouvelle-Calédonie, Réseau International des Instituts

Pasteur, Unité d'Epidémiologie des Maladies Infectieuses, Nouméa,

Nouvelle-Calédonie

Full list of author information is available at the end of the article
} 


\section{Background}

Acute rheumatic fever (ARF) and rheumatic heart disease (RHD) represent the first cause of cardiac mortality among children and young people in developing countries [1]. The worldwide prevalence of RHD is estimated at 15.6 million people, with an annual incidence of ARF of 470,000 . The burden of mortality still concerns 230,000 people per annum, caused by infective endocarditis and heart failures [2].

Since the 1980s, recommendations of the World Health Organization (WHO) promote secondary prevention as the cornerstone of control programs [3]. Secondary prevention of rheumatic fever is defined as the continuous administration of specific antibiotics to patients with a previous attack of rheumatic fever, or well-documented rheumatic heart disease. The purpose is to prevent colonization or infection of the upper respiratory tract with group A beta-hemolytic streptococci and the development of recurrent attacks of rheumatic fever [4]. Secondary prevention is considered to be the most cost-effective strategy to reduce mortality and morbidity [4]. Based on local and central registers, its objectives are to identify new cases of ARF and RHD, standardize and improve the diagnosis, management and follow-up of the patients, train health agents and communities to ARF, and maximize the administration of secondary prophylaxis $[5,6]$. The recommended secondary prophylaxis consists of intramuscular injections of benzathine benzylpenicillin G (BPG), every three to four weeks, the dosage being adapted to patient's weight [7]. Patients with proven penicillin allergy should be managed with twice-daily oral erythromycin [4]. Recommendations on the frequency of intramuscular injections and the duration of secondary prophylaxis vary between authorities.
The WHO does not specify whether injections should be administered every 3 weeks or every 4 weeks. The appropriate duration of secondary prophylaxis is determined by a number of factors, including age, time since the last episode of ARF, ongoing risk of streptococcal infections and potential harm from recurrent ARF $[4,8,9]$. Its effectiveness in reducing rates of streptococcal pharyngitis, recurrences of ARF and the progression of RHD is clearly assessed, and might even lead to a regression of mild to moderate valvular lesions within a decade [10-12].

Nevertheless, poor adherence to treatment is the main impediment to secondary prevention. Defined as the concordance between the patient's behavior and the care provider's recommendations [13], adherence is a rate that can range from 0 to more than $100 \%$ [14]. Global adherence to treatment of chronic diseases in developed countries averages only 50\%, particularly affecting the poor population. As many factors interact and interfere with adherence, it is considered as a multidimensional phenomenon [15].

Multiple measures of adherence to secondary prophylaxis of ARF were assessed since the 1970s, using various tools, such as the annual rate of BPG injections, the percentage of positive-for-penicillin urines, or the time interval and attendance at visiting specialist and echocardiographic appointments, but only few studies aimed at determining the factors associated to adherence [16-21]. Even though the level of adherence required to prevent further episodes of ARF is not known, the objective is to reach $100 \%$ of the annual expected BPG injections, with a recommended benchmark of $80 \%$ [9]. Patients receiving less than $80 \%$ of prescribed doses are considered at high risk of recurrence of ARF [6].

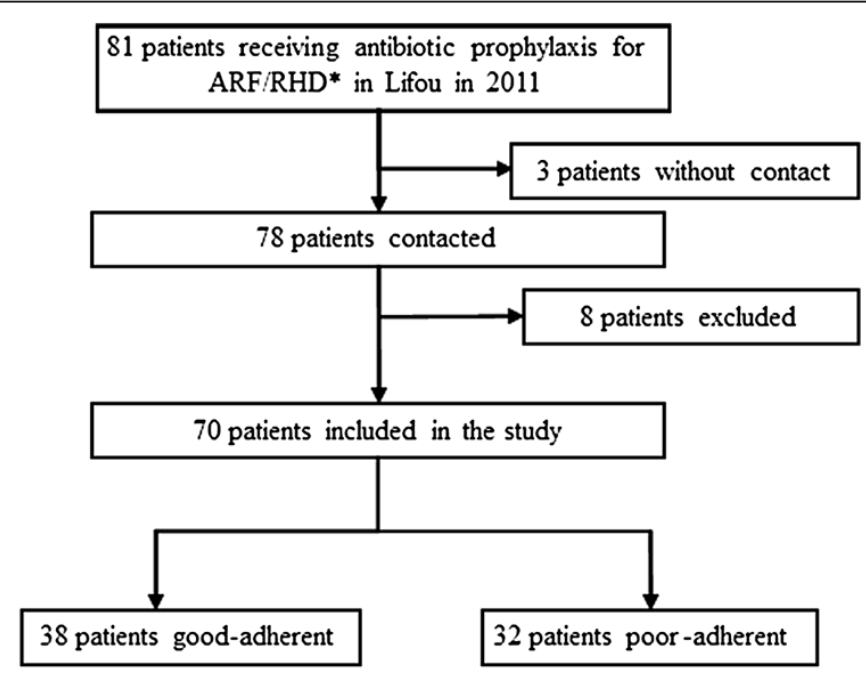

* $\mathrm{ARF}=$ Acute Rheumatic Fever; $\mathrm{RHD}=$ Rheumatic Heart Disease

Figure 1 Flow chart of the enrollment of subjects, Lifou, New Caledonia, 2011. 
It is in the Pacific region that the highest prevalences of RHD in the world are found [22]. In New Caledonia, the prevalence of RHD was estimated at 9/1,000 in school-children in their fourth year of primary school [23] but there are no data relating to the level of adherence. The objectives of this study were to evaluate rates of adherence in people receiving BPG injections prophylaxis in Lifou and to determine the factors associated with a poor adherence in this population.

\section{Methods}

\section{Ethics statement}

Ethical clearance was obtained from the Public Health and Social Agency of New Caledonia (Agence Sanitaire et Sociale de la Nouvelle-Calédonie). The study was also approved by the French consultative committee for the data processing in health research (Comité Consultatif sur le Traitement de l'Information en matière de Recherche dans le domaine de la Santé, CCTIRS). Informed written consent was obtained from adults or from the child's parents before conducting the interviews and after reading them information about the study. All data analyzed were confidential.

\section{Setting}

The study took place in the tropical island of Lifou, located $100 \mathrm{~km}$ from New Caledonia's main island, a French territory in the South Pacific. With a surface of $1,200 \mathrm{~km}^{2}$ and a population of 8,627 inhabitants (Census 2009, New Caledonian Institute for Statistics and Economics, ISEE), Lifou is divided into three districts and 37 tribes. Population is comprised of $96 \%$ of Melanesian whose income comes mainly from agriculture. According to ISEE $52 \%$ of the households are considered poor by the local criteria (Monthly household income $<75,000$ XPF $=$ 800 USD). Dwellings can be concrete, semi-concrete or traditional huts, mostly water and electricity-supplied. The main religion is Protestantism. The health care system includes two public health centers (We and Xepenehe), two private general practitioners (GPs) and a few private nurses. There is a nurse designated for the ARF prevention program, in Lifou acting as a link between the health agency in charge of the ARF prevention program based in the main island and local health professionals. There are no cardiologists or radiologists. Patients sometimes need to travel to the main island of New Caledonia by plane or ferry to attend the recommended annual echocardiography. Social security coverage is provided if the RHD is declared to the social welfare system. Patient with an adequate healthcare coverage do not have to advance medical expenses for the access to a cardiologist for regular follow up visits. . Otherwise, a copayment is required. Administration of BPG injections is free of charge, regardless of the patient's medical coverage.

\section{Study design}

We conducted a retrospective cohort study in Lifou and we included all patients receiving BPG injections prophylaxis over at least a period of 12 consecutive months, from the $1^{\text {st }}$ of January 2011 to the $31^{\text {st }}$ of December 2011.

The WHO adherence project has adopted the following definition of adherence to long-term therapy: " the extent to which a person's behaviour - taking medication, following a diet, and/or executing lifestyle changes, corresponds with agreed recommendations from a health care provider [15]. In our study, the rate of adherence was obtained by dividing the number of injections of BPG administered by

Table 1 Characteristics of the $\mathbf{7 0}$ patients receiving antibiotic prophylaxis to prevent acute rheumatic fever recurrence, Lifou, New Caledonia, 2011

\begin{tabular}{lcc}
\hline Characteristics & no./total no. & $\%$ \\
\hline Rate of adherence & & \\
\hline$<50 \%$ & $12 / 70$ & $(17)$ \\
$50 \%-79 \%$ & $20 / 70$ & $(29)$ \\
$\geq 80 \%$ & $38 / 70$ & $(54)$ \\
\hline
\end{tabular}

\begin{tabular}{|c|c|c|}
\hline \multicolumn{3}{|l|}{ Age - year } \\
\hline Median (Interquartile Range) & 17 & $(13-32)$ \\
\hline \multicolumn{3}{|l|}{$>16$ years old } \\
\hline No & $40 / 70$ & (57) \\
\hline Yes & $30 / 70$ & $(43)$ \\
\hline \multicolumn{3}{|l|}{ Sex } \\
\hline Female & $44 / 70$ & (63) \\
\hline Male & $26 / 70$ & (37) \\
\hline \multicolumn{3}{|l|}{ Ethnicity } \\
\hline Mixed-origin* & $4 / 70$ & (6) \\
\hline Melanesian & $66 / 70$ & (94) \\
\hline \multicolumn{3}{|l|}{ Disctrict of residence } \\
\hline Wetr & $41 / 70$ & (59) \\
\hline Gaïcha & $10 / 70$ & (14) \\
\hline Lossi & 19/70 & $(27)$ \\
\hline \multicolumn{3}{|l|}{ Household income } \\
\hline$\geq 150,000$ XPF (1,600 USD) / month & $43 / 67$ & (64) \\
\hline$<150,000$ XPF (1,600 USD) / month & $24 / 67$ & (36) \\
\hline \multicolumn{3}{|l|}{ Religion } \\
\hline Catholic & $12 / 70$ & (17) \\
\hline Protestant & $49 / 70$ & $(70)$ \\
\hline Other & $9 / 70$ & (13) \\
\hline \multicolumn{3}{|l|}{ History of acute rheumatic fever } \\
\hline No & $13 / 70$ & (19) \\
\hline Yes & $57 / 70$ & (81) \\
\hline \multicolumn{3}{|l|}{ Diagnosis of rheumatic heart disease } \\
\hline No & $16 / 70$ & (23) \\
\hline Yes & $54 / 70$ & (77) \\
\hline
\end{tabular}

* Mother or father of Melanesian origin. 
the number of the expected injections in $2011(n=17)$, considering a frequency of 3 weeks. This 3 weekly frequency is the frequency recommended by the Caledonian health agency in charge of the ARF prevention program at the time of this study. Patients were then classified as "poor-adherent" when the rate of adherence was $<80 \%$ of the expected injections and as "good-adherent" when it was $\geq 80 \%[6,9]$.

\section{Data collection}

Data were collected from patients' medical records and through a standardized questionnaire administered face to face by a single interviewer (BG). The questionnaire went through a pilot phase for 10 persons. For very young children, one of the parents at least was interviewed. For children aged less than 16 years old and able to understand the questions, we interviewed the child and one of his parents at least. We collected information about demographic and socio-economic characteristics, health care team and system-related factors, condition-related factors, therapyrelated factors and patient related-factors, according to WHO recommendations [24]. All questions were closeended with binary choices. To prevent information bias, we limited questions $(\mathrm{n}=3)$ referring to patient recall (minimal information on ARF/RHD, reason for not taking the medication, hospitalization at diagnosis).

\section{Statistical analysis}

Statistical analysis was performed by using Stata Statistical Software Release 11 (StataCorp. 2009, College Station, TX: StataCorp LP). Continuous variables were summarized using means \pm standard deviation or median and interquartile range (IQR). Frequencies of potential factors between good-adherent and poor-adherent patients were compared by Fisher's exact test. All statistical tests were two-tailed, and $\mathrm{p}$ values of less than 0.05 were considered to indicate statistical significance. We used logistic regression to examine the association between potential factors and the likelihood of a favorable outcome. Odds ratios (OR) and 95 percent confidence intervals (CI) were used to quantify the strength of these associations. Variables with a two-sided $\mathrm{p}$ value $<0.25$ were introduced in the multivariable logistic regression model. Multiplicative interactions were tested for their significance at the 0.05 level. A backward stepwise method was used to develop an optimal multivariable logistic model. Stata software includes automatic checks for collinearity. The Hosmer-Lemeshow goodness-of-fit test was used to evaluate the final regression model.

\section{Results}

Baseline characteristics of the population study

A total of 81 persons with a history of ARF or RHD and taking antibiotic prophylaxis in 2011 were identified in Lifou, given a prevalence of 9.4/1,000 inhabitants. Among them, 11 were excluded: three were unreachable, three took oral antibiotic prophylaxis and five started antibiotic in the year 2011 (Figure 1). In the end, 70 patients were included in the study and the participation rate was $100 \%$. The mean age of our population sample was $22.3 \pm$ 11.6 years, $43 \%$ were children aged less than 16 years old and $63 \%$ were female. Baseline characteristics of our population are presented in Table 1.

Our study showed that there were 38 good-adherent patients (54\%) and 32 poor-adherent patients (46\%) (Figure 2). The mean adherence to secondary prophylaxis was $77 \% \pm 22$ and the median adherence was $82.2 \%$ (IQR 76.5-94.1). The median number of injections was 14 (range 2-18).

Public health centers followed up 65 patients, GPs followed up the remaining five. The mean distance between the house and the nearest health center was $12 \mathrm{~km} \pm 10.8$.




Table 2 Univariate analysis comparing good-adherent to poor-adherent patients, Lifou, New Caledonia, 2011

Characteristics

Good-adherent patients $\mathrm{n} / \mathrm{N}(\%)$
No

Yes

Male sex

$$
\text { No }
$$

Yes

Concrete dwelling

No

Yes

Number of persons in the household $\geq 6$

No

Yes

Other case(s) of ARF in the household

No

Yes

Household income <150 000 CFP (1,600 USD)/month

No

Yes

Health care team and system-related characteristics

Follow up of ARF/RHD in a health center

No

Yes

Follow up of ARF/RHD in the health center of Xépénéhé

No

Yes

Distance between the residence and the nearest health center $>5 \mathrm{~km}$

No

Yes

Duration for an injection $>3 \mathrm{~h}$ §

No

Yes

BPG injections' recall system ^

No

Yes

Adequate healthcare coverage

No

Condition-related characteristics

Previous history of ARF

No

Yes
18/38 (47)

20/38 (53)

$21 / 38(55)$

17/38 (45)

25/38 (66)

$13 / 38$ (34)

$13 / 38(24)$

25/38 (66)

30/37 (81)

7/37 (19)

14/38 (37)

24/38 (63)

3/38 (8)

$35 / 38(92)$

13/35 (37)

22/35 (63)

14/38 (37)

24/37 (63)

23/29 (79)

$6 / 29(21)$

$37 / 37(100)$

$0 / 37(0)$

8/37 (22)

29/37 (78)
Poor-adherent patients

$\mathrm{n} / \mathrm{N}(\%)$

P value ${ }^{*}$

Palue

22/32 (69)

$10 / 32(31)$

23/32 (72)

9/32 (28)

18/32 (56)

$14 / 32(44)$

19/32 (59)

13/32 (41)

29/32 (91)

3/32 (9)

10/29 (34)

19/29 (66)

2/32 (6)

30/32 (94)

17/30 (57)

13/30 (43)

6/32 (19)

26/32 (81)

24/26 (92)

2/26 (8)

28/32 (88)

4/32 (12)

14/32 (44)

18/32 (56) 
Table 2 Univariate analysis comparing good-adherent to poor-adherent patients, Lifou, New Caledonia, 2011 (Continued)

\begin{tabular}{|c|c|c|c|}
\hline Previous history of RHD & & & 1 \\
\hline No & $9 / 38(24)$ & $7 / 32(22)$ & \\
\hline Yes & 29/38 (76) & $25 / 32(78)$ & \\
\hline Severe RHD at diagnosis ${ }^{* *}$ & & & 1 \\
\hline No & $25 / 29(86)$ & 19/22 (86) & \\
\hline Yes & $4 / 29(14)$ & $3 / 22(14)$ & \\
\hline Hospitalization at diagnosis of ARF or RHD & & & 0.813 \\
\hline No & 18/36 (50) & $17 / 32(53)$ & \\
\hline Yes & $18 / 36(50)$ & $15 / 32(47)$ & \\
\hline \multicolumn{4}{|l|}{ Therapy-related characteristics } \\
\hline Treatment duration $>2$ years & & & 0.743 \\
\hline No & $5 / 37(14)$ & $6 / 32(19)$ & \\
\hline Yes & $32 / 37(86)$ & $26 / 32(81)$ & \\
\hline Severe pain from BPG injection" & & & 0.130 \\
\hline No & $36 / 38(95)$ & $26 / 32(81)$ & \\
\hline Yes & $2 / 38(5)$ & 6/32 (19) & \\
\hline Desire for oral treatment & & & 1 \\
\hline No & $32 / 38(84)$ & $24 / 28(86)$ & \\
\hline Yes & $6 / 38(16)$ & 4/28 (14) & \\
\hline Confidence in treatment & & & 0.316 \\
\hline No & $1 / 36(3)$ & $3 / 29(10)$ & \\
\hline Yes & $35 / 36(97)$ & $26 / 29(90)$ & \\
\hline \multicolumn{4}{|l|}{ Patient-related characteristics } \\
\hline Protestant religion & & & 0.602 \\
\hline No & 10/38 (26) & $11 / 32(34)$ & \\
\hline Yes & 28/38 (74) & $21 / 32(66)$ & \\
\hline Knowledge of treatment's objectives & & & 1 \\
\hline No & $2 / 32(6)$ & $2 / 27(7)$ & \\
\hline Yes & $30 / 32(94)$ & $25 / 27(93)$ & \\
\hline
\end{tabular}

$\mathrm{Cl}$ denotes confidence interval, ARF denotes acute rheumatic fever and RHD denotes rheumatic heart disease.

*P values were calculated with the use of Fisher's exact test for categorical variables and Student's test for continue variables.

$\S$ The duration includes transport from home to health center, way and back. Patients having injections at home were excluded.

I Declarative information.

** The classification of severity was obtained by echocardiography medical records.

A fifth (21\%) of the patients was administered injections at home. A total of 57 patients had a history of ARF, including 3 cases of chorea. Among the 54 patients with a previous history of RHD, 8 were diagnosed during an echographic screening. The mean duration of treatment was $6.4 \pm$ 4.9 years. The majority of people trusted the treatment $(94 \%)$ and didn't want to switch for an oral antibiotic prophylaxis (85\%). Results of the univariate analysis comparing goodadherent and poor-adherent are presented in Table 2.

\section{Multivariate analysis}

The logistic non-conditional multivariate analysis identified three independent protective factors of poor adherence: a household with more than five people (OR, 0.25; 95\% CI, 0.08 to 0.75 ), a previous medical history of symptomatic ARF (OR, 0.20; 95\% CI, 0.04 to 0.98) and an adequate healthcare coverage (OR, $0.21 ; 95 \%$ CI 0.06 to 0.72 ) (Table 3).

\section{Discussion}

To our knowledge, this is the first study evaluating rates and determinants of adherence to secondary antibiotic prophylaxis for ARF recurrence in New Caledonia. Our study showed that there were 38 good-adherent patients (54\%) and 32 poor-adherent patients (46\%) in Lifou. This means that $46 \%$ of these patients with a previous 


\begin{tabular}{|c|c|c|}
\hline Variables & $\begin{array}{l}\text { Odds Ratio } \\
(95 \% \mathrm{Cl})\end{array}$ & P Value* \\
\hline Number of persons in the household $\geq 6$ & & 0.014 \\
\hline No & 1 & \\
\hline Yes & $0.25(0.08-0.75)$ & \\
\hline Previous history of ARF & & 0.047 \\
\hline No & 1 & \\
\hline Yes & $0.20(0.04-0.98)$ & \\
\hline Adequate healthcare coverage & & 0.013 \\
\hline No & 1 & \\
\hline Yes & $0.21(0.06-0.72)$ & \\
\hline
\end{tabular}

$\mathrm{Cl}$ denotes confidence interval, ARF denotes acute rheumatic fever. * $p$ values were calculated with the use of logistic-regression analysis. Variables candidates were : age $<16$ years old, male sex, distance from nearest health center $>5 \mathrm{~km}$, BPG injections' recall system, follow up of ARF/RHD in health center of Xépénéhé, severe pain from BPG injection, number of persons in the household $\geq 6$, previous history of ARF, full medical coverage. $p$ value was 0.67 by the Hosmer-Lemeshow test for goodness of fit.

history of ARF or RHD and receiving BPG injections were at high risk of recurrence of ARF.

The mean and median rate of adherence we found $(77 \%$ and $82.2 \%$ respectively) was lower than the one observed in India par Kumar et al. (mean adherence $>90 \%$ ), but was higher than those assessed in Australia by Stewart et al. (median rate of injections 54\%), by Eissa et al. in a remote Top End Aboriginal community (58\% of patients received $<80 \%$ of doses), by Mincham et al. in the Kimberley region in Western Australia (median adherence $=67 \%$ ) and by Seckeler et al. in Northern Mariana Islands (median adherence $=69.2 \%) \quad[16,18,19,21,25]$. A study conducted in Egypt showed that $64.6 \%$ of patients had an adherence $\geq 84 \%$, nevertheless the study samples can hardly be compared (20\% of children under oral antibioprophylaxis, injections of BPG delivered every 2 weeks) [17]. Ehmke et al.'s study in Iowa, where the overall adherence was $64.6 \%$, presents the same objections to comparison: paediatric population, oral antibioprophylaxis [26].

The wide range of indicators used in these different studies makes comparison particularly difficult and highlights the necessity of standardized indicators to evaluate adherence.

In our study, the multivariate analysis could determine three independent factors protectors of poor adherence: a demographic factor, $\geq 6$ individuals in the household; a health system-related factor, an adequate healthcare coverage; a condition-related factor, a previous history of symptomatic ARF. Two studies, conducted in the USA, tried to determine an association between the number of individuals of the household and the adherence. Gordis et al. in 1969, and Ehmke et al. in 1980 found that a large number of siblings was a risk factor of poor adherence $[26,27]$. In our study, we postulate that a large number of siblings in the household could improve the adherence probably because of the presence of a big brother or sister. They could accompany the child to the health center or take care of the household during the time of the consultation. This hypothesis is consistent with Gordis et al. study in which being unaccompanied by parent at clinical visits was associated with poor adherence. Mincham and Harrington, in two qualitative studies conducted in Australia, showed that an active recall system was a major determinant of adherence $[28,29]$. This secondary prevention strategy is indeed highly recommended by the WHO and the World Heart Federation $[4,6]$.

The association between the cost of medication and a poor adherence affects particularly low income populations [15,30-32]. To our knowledge no study ever analyzed this association in secondary prophylaxis to ARF and RHD, probably because it is usually free of charge in most countries. In Lifou, BPG injections are free but the copayment required for cardiologist reviews and transports to the cardiologist might have led to a negative perception of the health system and a feeling of not "belonging" to the health service. According to Harrington and Mincham, those representations of health system were responsible of poor adherence among Aboriginal patients [28,29]. An adequate healthcare coverage might be the consequence of a good adherence. Indeed, good adherent patients having frequent interactions with health staff could have a better track of their administrative and medical record.

Patients with a previous history of symptomatic ARF had a better adherence than patients who were diagnosed with RHD without history of ARF. It is described that among chronic diseases, asymptomatic diseases (diabetes, hypertension, osteoporosis...) are more likely to generate poor adherence [15]. Patient's perception of the disease gets modified by the existence of symptoms and the level of disability. Gordis et al. determined that having ARF with "no restriction of activity" was a risk factor of poor adherence among children [33]. Fear of recurrence of intense and painful symptoms might enhance adherence, unlike those diagnosed with RHD without history of ARF. Health education and sensitization in order to modify risks perception shall therefore be promoted.

Our retrospective cohort study of patients receiving antibiotic prophylaxis for ARF recurrence in Lifou was quite exhaustive; three patients only could not be contacted. A single investigator (BG) interviewed patients and collected data, therefore limiting the risk of variability. The study was led on a small island where all the health structures could be visited, which facilitated the data collection. By screening data, this study allowed us to register three new patients in the local register, to realize numerous demands for full medical coverage, to update medical and personal data and to provide information to cease two patients' antibiotic 
prophylaxis. Nevertheless, one of the limitations of this study, beside its retrospective design, was the sample size, resulting in a lack of statistical power. Another limitation was that we were not able to perform a sub-group analysis comparing children aged less than 16 years and adults because of the small sample size giving a lack of power.

\section{Conclusions}

To improve adherence to secondary prophylaxis in Lifou, we therefore propose the following recommendations arising from the results of this study: i) identifying patients receiving antibiotic prophylaxis without medical history of ARF to strengthen their therapeutic education and ii) improving the medical coverage in patients with ARF or RHD. Moreover, regarding the difficulty to identify ARF/RHD patients and to collect data on the dates of injections during the study, we also recommend that the nurse designated for the ARF prevention program in Lifou coordinate an active recall system based on an updated local register. Further epidemiologic research to better answer the question as to what makes some patients adhere to their injection and others not are needed. This might include a study on the main island of New Caledonia with a bigger sample size and a randomized study evaluating an intervention. But the key point to improve adherence among Melanesian patients is probably to give appropriate information regarding the disease and the treatment, taking into account the Melanesian perceptions of the disease.

\section{Abbreviations \\ ARF: Acute rheumatic fever; RHD: Rheumatic heart disease; GP: General practitioner; WHO: World Health Organization.}

\section{Competing interests}

Bernard Rouchon is the director of the Agence Sanitaire et Sociale which leads the rheumatic fever prevention program in New Caledonia.

\section{Authors' contributions}

BG and EDO conceived the study and questionnaire, carried out the data collection, interpreted the data, and drafted the manuscript. EDO did the analysis. NB participated in the design of the study and questionnaire and helped to draft the manuscript. BR participated in the design of the study and questionnaire and in the data collection. JMM participated in the data collection and revised the manuscript. IdF participated in the data collection and revised the manuscript. All authors participated, read and approved the final manuscript.

\footnotetext{
Acknowledgments

We are very grateful to the patients and their families who accepted to answer our questionnaire, and to all the inhabitants of Lifou. We would like to thank Louise Wapotro, Adeline Gomez, Wamo Wadrenges, Céline Mignet and Sara Cousin for finding and leading us to the patients. We thank the Circonscription Médico-Sociale of Drehu and the nurses for their contribution. We thank all the health centers and hospitals of New Caledonia for their participation, as well as all the cardiologists. We are very grateful to Agnes Germain, Mrs Christine Salomon, Mr Patrice Godin, Dr Jacques-Yves Langlet, Dr Yves Perroy, Dr Mariana Mirabel, Dr Andrew Steer and Daniel Bretodeau for their investment and Suzanne Chanteau (director of Institut Pasteur of New Caledonia) for her continual support in the rheumatic fever program research. We thank the Clinical Research Committee of Institut Pasteur Paris for their support.
}

\section{Financial support}

This work was supported by Institut Pasteur de Nouvelle-Calédonie and Direction de l'Action Communautaire et de l'Action Sanitaire de la Province des lles, Nouvelle-Calédonie.

\section{Author details}

${ }^{1}$ Centre médical de Wé, Circonscription médico-sociale de Drehu, Direction de l'Action Communautaire et de l'Action Sanitaire de la Province des lles, Nouméa, Nouvelle-Calédonie. ${ }^{2}$ Institut Pasteur de Nouvelle-Calédonie, Réseau International des Instituts Pasteur, Unité d'Epidémiologie des Maladies Infectieuses, Nouméa, Nouvelle-Calédonie. ${ }^{3}$ Agence Sanitaire et Sociale de la Nouvelle-Calédonie, Cellule du Rhumatisme Articulaire Aigu, Nouméa, Nouvelle-Calédonie. ${ }^{4}$ Cabinet de Cardiologie, Nouméa, Nouvelle-Calédonie. ${ }^{5}$ Direction de I'Action Communautaire et de l'Action Sanitaire de la Province des lles, Nouméa, Nouvelle-Calédonie.

Received: 19 September 2012 Accepted: 8 February 2013 Published: 12 February 2013

\section{References}

1. Marijon E, Mirabel M, Celermajer DS, Jouven X: Rheumatic heart disease. Lancet 2012, 379:953-964.

2. Steer AC, Carapetis JR, Nolan TM, Shann F: Systematic review of rheumatic heart disease prevalence in children in developing countries: the role of environmental factors. J Paediatr Child Health 2002, 38:229-234.

3. World health organisation: WHO programme for the prevention of rheumatic fever/rheumatic heart disease in 16 developing countries: report from Phase I (1986-90). Bull World Health Organ 1992, 70:213-218.

4. WHO Expert Consultation on Rheumatic Fever and Rheumatic Heart Disease: Rheumatic fever and rheumatic heart disease: report of a WHO Expert Consultation, Geneva, 29 October - 1 November, 2001):: Geneva Switzerland; 2001. 2004.

5. McDonald M, Brown A, Noonan S, Carapetis JR: Preventing recurrent rheumatic fever: the role of register based programmes. Heart 2005, 91:1131-1133.

6. World Heart Federation: Diagnosis and Management of Acute Rheumatic Fever Rheumatic Heart Disease. Geneva: World Heart Federation before; 2007. updated in 2008.

7. Manyemba J, Mayosi BM: Intramuscular penicillin is more effective than oral penicillin in secondary prevention of rheumatic fever-a systematic review. S Afr Med J 2003, 93:212-218.

8. Gerber MA, Baltimore RS, Eaton CB, Gewitz M, Rowley AH, Shulman ST, Taubert KA: Prevention of rheumatic fever and diagnosis and treatment of acute Streptococcal pharyngitis: a scientific statement from the American Heart Association Rheumatic Fever,

Endocarditis, and Kawasaki Disease Committee of the Council on Cardiovascular Disease in the Young, the Interdisciplinary Council on Functional Genomics and Translational Biology, and the Interdisciplinary Council on Quality of Care and Outcomes Research: endorsed by the American Academy of Pediatrics. Circulation 2009, 119:1541-1551.

9. RHD Australia (ARF/RHD writing group) National Heart Foundation of Australia and the Cardiac Society of Australia and New Zealand: Australian guideline for prevention, diagnosis and management of acute rheumatic fever and rheumatic heart disease. 2nd edition. RHDAustralia: Menzies School of Health Research; 2012.

10. Steer AC, Colquhoun S, Kado J, Carapetis JR: Secondary prophylaxis is important for the prevention of recurrent rheumatic fever in the Pacific. Pediatr Cardiol 2011, 32:864-865.

11. Manyemba J, Mayosi BM: Penicillin for secondary prevention of rheumatic fever. Cochrane Database Syst Rev 2002, CD002227.

12. Steer AC, Carapetis JR: Prevention and treatment of rheumatic heart disease in the developing world. Nat Rev Cardiol 2009, 6:689-698.

13. Haynes RB, Ackloo E, Sahota N, McDonald HP, Yao X: Interventions for enhancing medication adherence. Cochrane Database Syst Rev 2008, CD000011.

14. Osterberg L, Blaschke T: Adherence to medication. N Engl J Med 2005, 353:487-497.

15. World Health Organisation: Adherence to long-term therapies. Evidence for action. Geneva, Switzerland: World Health Organization; 2003. 
16. Kumar R, Thakur JS, Aggarwal A, Ganguly NK: Compliance of secondary prophylaxis for controlling rheumatic fever and rheumatic heart disease in a rural area of northern India. Ind Heart J 1997, 49(3):283-288.

17. Bassili A, Zaher SR, Zaki A, Abdel-Fattah M, Tognoni G: Profile of secondary prophylaxis among children with rheumatic heart disease in Alexandria, Egypt. East Mediterr Health J 2000, 6:437-446.

18. Stewart T, McDonald R, Currie B: Acute rheumatic fever: adherence to secondary prophylaxis and follow up of Indigenous patients in the Katherine region of the Northern Territory. Aust J Rural Health 2007, 15:234-240.

19. Mincham CM, Mak DB, Plant AJ: The quality of management of rheumatic fever/ heart disease in the Kimberley. Aust N Z J Public Health 2002, 26:417-420

20. Pelajo CF, Lopez-Benitez JM, Torres JM, de Oliveira SK: Adherence to secondary prophylaxis and disease recurrence in 536 Brazilian children with rheumatic fever. Pediatr Rheumatol Online J 2010, 8:22.

21. Eissa S, Lee R, Binns P, Garstone G, McDonald M: Assessment of a registerbased rheumatic heart disease secondary prevention program in an Australian Aboriginal community. Aust N Z J Public Health 2005, 29:521-525

22. Colquhoun SM, Carapetis JR, Kado JH, Steer AC: Rheumatic heart disease and its control in the Pacific. Expert Rev Cardiovasc Ther 2009, 7:1517-1524.

23. Baroux N, Rouchon B, Huon B, Germain A, Meunier JM, D'Ortenzio E: High prevalence of rheumatic heart disease in schoolchildren detected by echocardiography screening in New Caledonia. J Paediatr Child Health 2013. doi: 10.1111/jpc.12087.

24. WHO: Adherence to long-term therapies. Evidence for action. Geneva: World Health Organization; 2003.

25. Seckeler MD, Hoke TR, Gurka MJ, Barton LL: No demonstrable effect of benzathine penicillin on recurrence of rheumatic Fever in pacific island population. Pediatr Cardiol 2010, 31:849-852.

26. Ehmke DA, Stehbens JA, Young L: Two studies of compliance with daily prophylaxis in rheumatic fever patients in lowa. Am J Public Health 1980, 70:1189-1193.

27. Gordis L, Markowitz M, Lilienfeld AM: Studies in the epidemiology and preventability of rheumatic fever. IV. A quantitative determination of compliance in children on oral penicillin prophylaxis. Pediatrics 1969, 43:173-182.

28. Harrington Z, Thomas DP, Currie BJ, Bulkanhawuy J: Challenging perceptions of non-compliance with rheumatic fever prophylaxis in a remote Aboriginal community. Med J Aust 2006, 184:514-517.

29. Mincham CM, Toussaint S, Mak DB, Plant AJ: Patient views on the management of rheumatic fever and rheumatic heart disease in the Kimberley: a qualitative study. Aust J Rural Health 2003, 11:260-265.

30. Ellis JJ, Erickson SR, Stevenson JG, Bernstein SJ, Stiles RA, Fendrick AM: Suboptimal statin adherence and discontinuation in primary and secondary prevention populations. J Gen Intern Med 2004, 19:638-645.

31. Briesacher BA, Gurwitz JH, Soumerai SB: Patients at-risk for cost-related medication nonadherence: a review of the literature. J Gen Intern Med 2007, 22:864-871.

32. Eaddy MT, Cook CL, O'Day K, Burch SP, Cantrell CR: How patient costsharing trends affect adherence and outcomes: a literature review. PT 2012, 37:45-55.

33. Gordis L, Markowitz M, Lilienfeld AM: Why patients don't follow medical advice: a study of children on long-term antistreptococcal prophylaxis. J Pediatr 1969, 75:957-968.

doi:10.1186/1471-2458-13-131

Cite this article as: Gasse et al:: Determinants of poor adherence to secondary antibiotic prophylaxis for rheumatic fever recurrence on Lifou, New Caledonia: a retrospective cohort study. BMC Public Health 2013 13:131.

\section{Submit your next manuscript to BioMed Central and take full advantage of:}

- Convenient online submission

- Thorough peer review

- No space constraints or color figure charges

- Immediate publication on acceptance

- Inclusion in PubMed, CAS, Scopus and Google Scholar

- Research which is freely available for redistribution 